\title{
Do rito à festa: transformações contemporâneas das músicas do ritual Santiago nos Andes Centrais do Peru
}

Carlos Pérez Reyna ${ }^{1}$

\section{RESUMO}

O ritual do Santiago é uma comemoração privada - celebrada pelas famílias donas de gado vinculado à fertilidade animal e ao Wamani, uma deidade andina associada às montanhas dos Andes Peruanos. O papel que a música desempenha nesse ritual é de fundamental importância. Cada passo ou unidade ritual tem uma música particular e essencial para a cerimônia. O fato que esse tipo de música exclusiva só apareça nesse contexto, confirma a ideia de que o ritual Santiago é uma unidade indissociável de gesto e som, de rito e música. Entretanto, as músicas ritualísticas aqui revisitadas vêm atravessando deslocamentos e mudanças culturais próprias das transformações do sistema industrial, da modernização, da urbanização e dos meios de comunicação. Nesse sentido, este artigo apresentará algumas funções simbólicas, sociais e, as iniciais transformações contemporâneas das músicas desse rito. Tomaremos como base empírica o Santiago celebrado na comunidade camponesa de Auray (Andes Centrais do Peru).

Palavras chaves: Etnomusicologia, música ritual andina, mudança cultural.

From rite to feast: contemporary transformations of the music of the ritual Santiago in Central Andes of Peru

\section{ABSTRACT}

The Santiago ritual is a private celebration - celebrated by the families of cattle owners - linked to animal fertility and the Wamani, an Andean deity associated with the mountains of the Peruvian Andes. The role that music plays in this ritual is of fundamental importance. Each step or ritual unit has a particular and essential song for the ceremony. The fact that this type of exclusive music only appears in this context confirms the idea that the Santiago ritual is an inseparable unit of action and sound, of rite and music. However, the ritualistic songs revisited here have been going through cultural shifts and changes characteristic of the transformations of the industrial system, modernization, urbanization and the media. In this sense, this article will present some symbolic and social functions and the initial contemporary transformations of the songs of this rite and will take as an empirical basis the Santiago celebrated in the peasant community of Auray (Central Andes of Peru).

Key words: Ethnomusicology, Andean ritual music, cultural change.

1 Professor do Programa de Pós-Graduação em Ciências Sociais (PPGCSO) da Universidade Federal de Juiz de Fora (UFJF) 


\section{A noção de Rito $^{2}$ nos Andes do Peru}

Os rituais ${ }^{4}$ andinos, frequentemente, são condutas formais, prescritas para certas cerimônias oferecidas a seres que possuem poderes míticos, como por exemplo: os Apus (montanha) e Pachamama (mãe terra). Neles, o camponês refaz seu pensamento e a consciência de seus limites perante a natureza e os seres que ele considera superiores. Como é bem conhecido, as sociedades andinas têm tido uma preocupação coletiva, por meio de gestos e palavras, mitos e ritos, em inventar medidas do tempo e modelos de organização do espaço (Arguedas, Rescanieri, 1965; Urbano, 1974, Rescanieri, 1985). Para expressar essa realidade de maneira proveitosa, segundo a lógica do gesto ritual, ele celebra seus ritos correspondentes invocando sistematicamente seus seres especiais (um espírito ou um ser especial), nos quais ele acredita encontrar a forma de realização perfeita. É por isso que o ritual andino periodicamente readapta o indivíduo às condições fundamentais, aos valores axiomáticos da vida social, fazendo-o escolher os elementos mais significativos de seu cotidiano para, por exemplo, distinguir o que é ou não essencial - ou necessário - para sua colheita ou criação de gado, fazendo-o atemorizar-se com a seca ou com as doenças. Sendo assim, no caso presente, os ritos refletem as necessidades, preocupações e intenções do homem andino.

Nesses ritos não podem estar ausentes gestos e processos que são uma expressão ancestral e que, por isso mesmo, por sua existência desde épocas distantes, foram objeto de estudos e da curiosidade por parte dos cronistas espanhóis. O gesto ritual como símbolo religioso andino, assim como o discurso contemporâneo, traduzem a existência de uma experiência histórica singular que, por sua vez, foi evoluindo com o tempo.

Segundo os estudiosos da religião andina, após a chegada dos espanhóis no século XVI, no Peru se produziu uma espécie de fusão entre os sistemas de crenças e práticas religiosas existentes e a religião católica trazida pelos espanhóis. Essa situação persiste hoje, se bem que transformada pela ação dos acontecimentos. Manuel Marzal, em sua publicação El sincretismo iberoamericamo, ao descrever os sistemas religiosos dos Incas de Cuzco, elabora uma teoria sobre todas as formas de sincretismo no encontro de religiões:

Quando duas religiões têm um longo contato, não se confundem em uma única (síntese), ou conservam sua identidade de modo independente (justaposição), senão que formam uma nova, cujos elementos (crenças, ritos, formas de organização e suas normas éticas) são produtos do encontro das duas religiões, nas quais certos elementos se identificam com seus similares, outros desaparecem por completo, outros permanecem tal como estavam e outros se reinterpretam, mudando seu próprio significado ou acrescentando outros (sincretismo) (1985, p. 76).

Eis noções que, por serem baseadas em alguns grupos indígenas de zonas rurais relativamente pequenas e bastante homogêneas, não esgotam seus sentidos. Mais do que simples influências e incorporação de "elementos" religiosos entre dois

2 Não é pretensão deste artigo fazer uma revisão histórica e crítica a respeito do rito. Um trabalho que revisa e analisa criticamente as tendências mais importantes do estudo antropológico do rito é dada pela antropóloga Nancy Munn em seu artigo "Symbolism in a ritual context: aspect of symbolic action", em Honigmann (ed.) Handbook of social and cultural anthropology, 1974. A autora propõe examinar o rito como "um intercomunicador simbólico entre o nível de significados culturais, por um lado, e as ações sociais e os eventos imediatos, por outro".

3 Este artigo tem por base a comunicação apresentada na conferência sobre "La Antropologia Visual y la Representación del Outro" realizado na Corte Superior de Justicia em Huancayo-Peru, 25/08/2016. É também, parte desmembrada de minha tese de doutoramento, corrigida e ampliada com os dados colhidos em estudos posteriores em 2015 e 2016. Uma versão inicial deste trabalho foi publicada com o título: "Ritual \& Música: as músicas do ritual Santiago nos Andes Centrais do Peru”, pela na Revista Transcultural de Música da Sociedade de Etnomusicologia, Trans 17 (2013). Esta é sua última versão como concebida inicialmente.

4 Para Mircea Eliade (1981), toda festa religiosa considerada como tempo litúrgico consiste na (re) atualização de um acontecimento sagrado que teve lugar num passado mítico, no "princípio". O tempo sagrado é, por conseguinte, indefinidamente recuperável. Segundo o autor, em cada festa periódica se reencontra o mesmo tempo sagrado manifestado na festa do ano precedente ou na festa de há um século ou mais. Diante disso, tentaremos transportar-nos ao mundo andino no qual existe uma percepção similar à mencionada anteriormente, embora com características muito próprias. 
sistemas de culto (o indígena e o espanhol), nos alinhamos com Carlos Brandão quando este diz:

O que está por baixo de tudo é a maneira como as religiões de um mesmo campo compartilham desigualmente uma mesma lógica de símbolos e sentidos do sagrado. Penso que o que importa considerar é como cada uma delas enfrenta, na outra, a questão de sua própria identidade. (1994, p. 187).

É o que acontece em quase toda área andina, onde as divindades Apus, Auquis (montanhas), Wamanis (espíritos das montanhas) convivem com as divindades católicas (Cristo crucificado, a Virgem Maria ou os santos).

Outrossim, o estudo dos rituais das festas andinas contemporâneas, além de levar-nos a pensar em situações mais ou menos similares à descrita, mostra-nos a diferença de que muitos desses ritos não só estão encobertos pela presença da experiência cristã, logo após a chegada dos espanhóis, mas também na prática:

\footnotetext{
O que se tem é uma complexa relação entre símbolos religiosos realizados como seres-de-relações, em que o que é acreditado em uma não é propriamente negado na outra, mas dentro da versão lógica da combinação dos elementos simbólicos de um repertório comum - e cuja contiguidade metafórica e metonímica é justamente o que dá a dinâmica a um campo religioso polissêmico - é requalificado (BRANDÃO, 1994, p.247).
}

Isso permite uma leitura intrigante em que duas religiões, quando estão inevitavelmente em contato íntimo, coexistam, não apenas incorporando elementos uma da outra, característica do sincretismo, mas produzindo novas combinações de sentidos.

Em resumo, os rituais podem definir-se como tempos e espaços socialmente demarcados em que formas simbólicas altamente elaboradas são apresentadas e representadas. Neles, certos símbolos sejam gestos e palavras, têm a capacidade de sintetizar significados socioculturais complexos que provêm de variados âmbitos e de contextos específicos, convertendo-se assim em veículos por meio dos quais se constroem mensagens e circulam significados. O ritual, nesse caso, tem como traço distintivo a dramatização, isto é, a condensação de algum aspecto, elemento ou relação, colocando-o em foco, tal como acontece nos rituais andinos. Para elaborar esta definição tomo a noção de intercomunicador simbólico de Nancy Munn (1974), a noção de condensação dos símbolos rituais utilizada por Victor Turner (1974) e o conceito semiótico, não da ciência do signo e da sintaxe, mas da Teoria do Significado a que Clifford Geertz (1989) se remete.

\section{O ritual Santiago na comunidade de Auray}

A comunidade camponesa de Auray situase no extremo sul do Vale do Rio Mantaro, na província de Huancayo, nos Andes Centrais do Peru. Sua altitude é de $3.218 \mathrm{mts}$. sobre o nível do mar e compõe-se aproximadamente de 2.500 pessoas. Suas atividades fundamentais são a agricultura e a pecuária. Embora seu processo de transformação seja cada vez mais intenso em função da penetração dos diferentes meios de produção, circulação, consumo e de comunicações, sua forma de vida encontra-se ainda enraizada segundo moldes tradicionais ancestrais.

Alguns historiadores dizem que antigamente os Wancas e os Incas habitavam essa região, mas esta não tinha um nome específico. As terras pertenciam ao inca e ao deus Inti (Sol). Com a chegada dos espanhóis, esses antigos povoadores começaram a livrar-se de seus artefatos em ouro e prata para evitar que estes caíssem nas mãos dos conquistadores. Podemos encontrar, também, vestígios de construções pré-hispânicas de cidades chamadas Wuari-Vilca e Quillis Qocha.

Por seu passado, Auray ainda conserva fragmentos de formas tradicionais de organização comunal, posto que não foi afetada pela reforma agrária de 1969. Cada momento agrário é festejado: a celebração do gado e a de seu santo padroeiro, geralmente é o apóstolo Santiago. Este último é o padroeiro do gado da comarca, mas também são os Wamanis, ou espíritos das montanhas do lugar. Os dois, montanha e santo, podem ter o mesmo valor, até mesmo são tratados como dois aspectos ou nomes de um mesmo personagem. Em algumas comunidades o santo substitui o Wamani; em outras, o santo 
seria apenas um apelativo do verdadeiro senhor do gado, o espírito da montanha, o ser superior. Sendo assim, é o gesto ritual que estabelece relações de aliança ou tributo que se paga a um ser considerado superior. Essa doação gratuita é o reconhecimento de um poder que está acima das forças humanas, pedido de comunhão ou expiação de uma falta qualquer que, de alguma forma, questiona o conjunto das relações entre os homens ou entre os seres humanos e os seres superiores.

Nesta posição, o ritual andino Santiago de Auray coloca-nos um problema de relações de correspondência entre a representação (imagens, signos e símbolos) do tempo e do espaço, dos gestos e das palavras, dos mitos e dos ritos que a festa Santiago traduz toda vez que se realiza. Seu caráter dramático é uma maneira de sublinhar profundamente que o gesto ritual deseja alcançar o evento ou ato como totalidade, embora irremediavelmente perdido.
Ressignificação atual do ritual Santiago relacionadoà marcação do gado na comunidade camponesa de Auray

Contemporaneamente, as práticas e crenças religiosas andinas na comunidade camponesa de Auray continuam subsistindo, mas não incólumes. Hoje, o panteão de deidades e protetores do gado segue o seguinte esquema de reinterpretações, a saber:

ASPECTO RELIGIOSO

SUBSISTÊNCIA DA RELIGIÃO

POPULAR ANDINA NA COMUNIDADE CAMPONESA DE AURAY

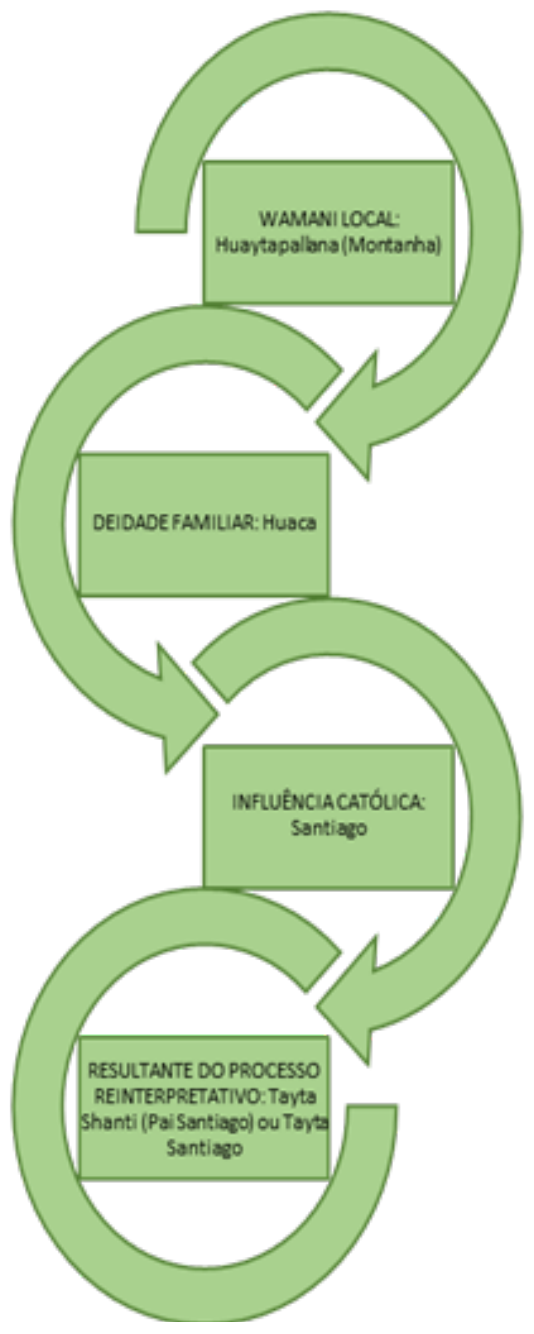


Apesar de parecer evidente, a comemoração do apóstolo, a festa de Santiago, não é uma celebração cristã. Não participam dela sacerdotes católicos ou se recitam prédicas dirigidas a Deus, à Virgem Maria ou aos santos. Ainda que o Santiago possua um altar na igreja local, não é visitado particularmente. As cerimônias não têm o caráter comunitário das festas patronais e/ou das principais celebrações religiosas.

O personagem principal da comemoração é o Wamani. A ele são oferecidos os ritos e sua principal finalidade é a preservação e o aumento do gado (vacas, carneiros, cavalos, mulas, porcos etc.). Ambos, santo e montanha, podem ser percebidos como equivalentes e são tratados como dois aspectos ou nomes de um mesmo personagem. Segundo o historiador e etnólogo Sérgio Quijada (1974), a festa de Santiago é considerada como o dia dos animais e dos pastores, tendo como fundamento a superstição de considerar o Tayta Wamani deus e senhor das montanhas. É costume pensarmos que o nativo rende culto às montanhas, sendo que essa celebração, em realidade, não é dirigida ao lugar, mas ao espírito que habita nelas, consagrado como hierofania ${ }^{5}$. A festa do Santiago não foi introduzida pelos espanhóis, mas à chegada deles os nativos tentaram seguir comemorando seus animais, desta vez, sob a tutela e proteção na representação do apóstolo. No que diz respeito às regras e cerimônias observadas no curso da festa de Santiago, os encarregados (sacerdotes andinos $)^{6}$ (Fig. 1) $)^{7}$ das celebrações são, em geral, zelosos do cumprimento dos costumes tradicionais.

A festa de Santiago na comunidade camponesa de Auray celebra-se, segundo o calendário cristão, no dia 25 de julho, e segundo o esquema desenvolve-se em duas fases continuadas: a véspera e o dia central. Eis sua reinterpretação hoje:
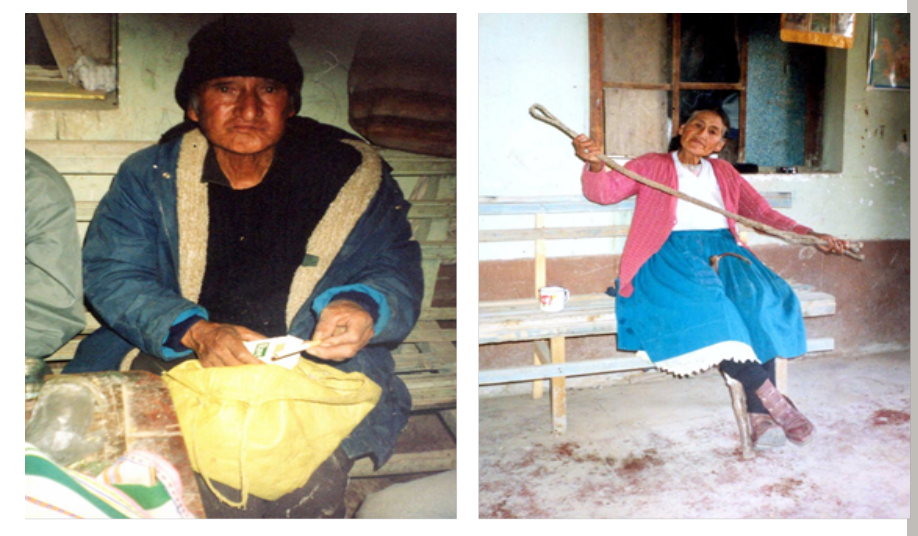

Fig. 1 “don” Juan Torres e dona Julia Orellana

5 Segundo Mircea Eliade, hierofania é a manifestação de uma entidade sagrada. Ver, O Sagrado e o Profano: A essência das religiões. São Paulo, Martins Fontes, 2001

6 Proprietários do gado, sacerdotes andinos (encarregados do rito) e principais informantes da pesquisa é constituída pela família Torres Orellana: Juan Torres (esposo), de 78 anos, e Julia Orellana (esposa), de 73 anos.

7 Acervo do autor. 


\section{Unidades rituais}

a) A véspera

- 0 Huaca-jorqoy (retirada das huacas): ritual de abertura praticado para lograr 0 consentimento, a bênção do deus tutelar.

- O Velakuy (a velada): a presença de imagens paralelas na mesa ritual caracteriza a simbiose entre 0 andino e o hispânico. As huacas, o quille, as flores e as imagens em miniatura de animais representam a fecundidade e conservação dos animais; o kokakintu é o pago em honra ao Wamani. Estes atos são conciliatórios, orientados a aplacar a ira do deus tutelar e, assim, evitar castigos como as perdas, as doenças, os acidentes ou as mortes dos animais.

\section{b) 0 dia central}

- Luci-Luci (luzeiro-luzeiro): consiste em saumar (chamuscar) a pança dos animais com forragem acesa. Embora os principais propósitos desse rito sejam propiciatórios, pelo inicio de um novo ano; de purificação e proteção do gado, para sua reprodução e afugento das doenças que afligem os animais, parece existir um jogo de imagens a partir da equivalência entre a fogueira do Luci-Luci e o luzeiro da alvorada. Na cerimônia, a fogueira é ferramenta mágica que o homem tem para lutar pela saúde do seu gado e contra o Wamani. Então, luzeiro é também arma do homem. Nesta oposição, o homem e suas forças estão do lado do dia, na medida em que devem vencer o Wamani, que está do lado da noite, e que graças ao Luci-Luci, perderá. Então, ao Luci-Luci, também poderíamos considerá-lo um ritual de passagem, passagem numinosa (onde o sagrado se manifesta no espaço). Estas ações estão associadas ao quarto minguante (Illllu quilla), variação da fase lunar protetora do gado.

- A mesa ritual de bênção: marca o final dos atos preparatórios e o início do Cintachikuy. Três práticas são realizadas: 0 chaccheo (mastigação da coca), o kinto (seleção das melhores folhas de coca) e a elaboração das cintas (vinculadas às cores do arco-íris, símbolo de reprodução, bonança, alegria e bom augúrio). Para os aurinos o arco-íris é um tempo de passagem transcendente. Como ato final, o sinal-da-cruz, realizado por dona Julia, é um gesto católico, mas seus pedidos são dirigidos ao Wamani.

- Cintachikuy ou ritual de marcação do gado: esse ritual é caracterizado por duas práticas: a sinalização do gado com as cintas coloridas e a colocação do kinto à beira do prato com chicha. As folhas do kinto simbolizam o gado em seu conjunto; o prato com chicha (soro simbólico) cumpre a função de proteção do Wamani contra as doenças; e sua separação à beira do prato serve como cômputo dos animais que serão reprodutores, longe do alcance das doenças. Suas intenções são o aumento do gado.

- Casarakuy (acasalamento simbólico): é realizado entre vaquilhonas - vacas que ainda não pariram -e homens jovens solteiros (walars). Este comportamento liminóide nos permite revelar a aceitação da ordem exatamente inversa dos princípios e estatutos rituais socialmente regulados da vida rotineira. É um rito que atesta a passagem da escassez à abundância. É executado para anular os efeitos da morte do gado que dona Julia sofreu no ano-calendário anterior e propiciar maior fertilidade no próximo. A manta colorida, como vimos anteriormente, está vinculada às cores do arco-íris, símbolo de reprodução, bonança, alegria e bom augúrio. 
As músicas ${ }^{8}$ do ritual Santiago em Auray: funções simbólicas e sociais

Quando "don" Juan nos diz que o Santiago "é uma festa para os animais", interpretamos que além de uma festa dedicada e realizada para os animais, o entendemos também como uma forma de comportamento ritual relacionado com os seres ou poderes míticos (TURNER, 1974). Isto é, vinculada exclusivamente à fertilidade do gado e ao Wamani. É por isso que, em tempos de Santiago, a música e o ritual são inseparáveis, posto que existe uma relação de correspondência entre unidade ritual e o tipo específico de música.

Das canções cujas letras reproduziremos neste artigo, algumas foram por nós registradas e outras foram descritas por outros autores, entre eles (QUIJADA, 1974). Sua transcrição do quíchua deve-se à colaboração de nosso colega antropólogo Juan Carlos Cóndor'. As canções são conhecidas geralmente pelo nome de "santiagos", embora na maioria dos casos tenham nomes particulares. Grosso modo, essa música possui uma base rítmica de $1 / 4$, marcado pelo batuque monótono da Tinya. E é cantada, fundamentalmente, pela cantora. Intermitentemente, os participantes, no geral os varões, irrompem a melodia introduzindo um falsete gritado chamado de "guapeada". A dança propriamente dita é executada por casais de homens e mulheres, separados ou de braços dados. A sequência de movimentos é caracterizada pelos giros, meios giros, sapateadas e pequenos pulos. Configura-se por intermédio de avanços contínuos em qualquer direção. Nessa dança, existe um jogo de puxões bruscos e súbitos que exerce cada dançante sobre sua parceira, tentando, a todo momento, atraí-la a seu terreno. É pouco frequente que os casais fiquem isolados; o habitual é que se trate de grupos de casais em movimento pelas ruas ou dentro dos lares. Esses grupos são chamados de "pandillas" (quadrilhas).

\section{Os músicos}

Os músicos do Santiago são, em geral, ou das comunidades altas do Vale do Rio Mantaro ou das comunidades dos departamentos da região sul dos Andes peruanos. São poucos os intérpretes da região baixa do Vale que sabem executar as melodias dessa festa. Sendo assim, a família Torres Orellana contratou os músicos da comunidade de Pariahuanca ${ }^{10}$ à base de trueque (troca). Os músicos são constituídos por componentes de uma mesma família ${ }^{11}$ (o pai, a mãe e o filho) (Fig. 2) ${ }^{12}$.

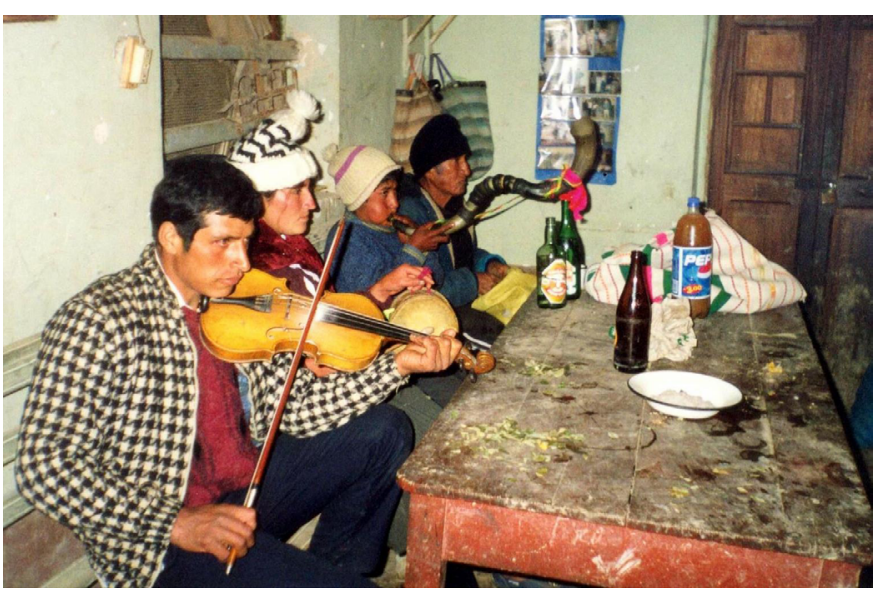

Fig. 2 Músicos e Instrumentos

Quando perguntamos a estes qual o custo do serviço deles, a resposta é imediata:

Cobramos 360 soles por quatro dias, mas decidimos fazer o trueque (troca) por batatas, favas e cevada; nossa última colheita foi péssima, então estamos necessitando desses produtos. Ano passado deu para levar algum dinheiro, mas dá igual porque

8 Como não é pretensão deste item fazer uma etnomusicologia das canções do Santiago, suas interpretações ficaram restritas apenas de maneira modesta às funções simbólicas e sociais das músicas no Santiago Aurino.

9 O antropólogo Juan Carlos Cóndor Ames é especialista sobre cosmovisão andina e professor na Universidade Nacional do Centro do Peru (UNCP), localizada no estado de Junín, província de Huancayo. Seu conhecimento apropriado da língua quíchua permitiu associar os gestos às sequências rituais bem como os termos correspondentes das letras às músicas ritualísticas. Seu apoio, companheirismo e informações a respeito da comunidade pesquisada foram fundamentais para a realização deste estudo.

10 Região alta do nordeste do Vale do Rio Mantaro.

11 Sobre a família de músicos, nossas informações são escassas. Quando começamos as entrevistas - um dia depois das filmagens do Santiago -, ficamos sabendo que eles tinham retornado a sua cidade.

12 Acervo do autor. 
temos que comprar os produtos em Pariahuanca, só que um pouco mais caro. Dona Julia sempre nos dá um pouquinho mais.

\section{Os instrumentos}

\section{- A Tinya}

O historiador Luis Valcárcel (1984) cita o padre Bernabé Cobo para mencionar que entre os instrumentos conhecidos do Peru antigo estava o huancar tinya (tambor, tinya, tamborim). Já Enrique Pinilla menciona que esses tambores eram de dois tipos "o pequeno (tinya) e o grande (huancar). Eram feitos de pele de lhama ou de outros animais e também com pele humana, geralmente dos inimigos derrotados" (1981:378379, vol. IX).

Uma descrição contemporânea da Tinya é dada por Quijada (1974), Castro (1979) e Fuenzalida (1980). Ela é como um tambor de madeira e de dupla camada de pele de cordeiro, cujo diâmetro varia entre os 13 e os 25 centímetros. Às vezes é enfeitado com borlas de lã colorida, com uma asa de corda por meio da qual se firma a mão sobre um dos cantos da madeira, para que assim as duas superfícies fiquem livres para a batida e a ressonância. Com respeito à Tinya, encontrada nesta pesquisa, é elaborada com pele de carneiro e comprada na Feira Dominical de Huancayo. No Santiago de Auray, esse instrumento é tocado pela cantora (cantante mulher), que bate com uma pequena vara de madeira denominada tinyaco ou huacctaco.

\section{- A Corneta Wakrapuku (Berrante)}

"As cornetas mais antigas próprias dessas festas sempre têm sido o yungor ou llungor (...), mas também é feito de carrizo (bambu) ou chonta branca (cacto), além das cornetas de chifre em forma de espiral" (QUIJADA, 1974:9). José Maria Arguedas descrevia: “(...) o llungur, gigantesco instrumento de sopro, originalmente feito de cana da selva" (1984, p. 44). Às exposições manifestas soma-se a experiência de Nestor Taipe, quando narra as crenças de algumas comunidades andinas do sul do Peru;

O llungur cresce em lugares 'ruins', lugares pantanosos; tem de ser apanhado só de manhã, do contrário pode causar 'daño' (mal) (...) não pode ser colhido qualquer dia, tem de ser em lua cheia, senão ele quebra. Existem dois tipos de llungur, o de gema vermelha tem bom som e a de gema verde, não (1982, p.113).

Sobre a corneta de Auray, é bastante comum chamá-la de wakrapuku ou pututo, e é feita de acumulação de espiral de partes prontas do chifre do boi e de metal. No geral, essas cornetas são tocadas pelos homens, no nosso caso pelo filho do casal. A particularidade desse instrumento é que só pode ser executado em Santiago. Quando a época do ritual se aproxima, o proprietário do wakrapuku deverá "preparar" o instrumento pelo fato de ter permanecido guardado o ano todo. Segundo o autor acima mencionado ainda existem, nas comunidades andinas do sul do Peru, regras e tabus para adquiri-las.

Atualmente os atos preparatórios para a comunidade de Auray foram transformados em novas formas de aquisição, vejamos: a comunidade camponesa de Auray e, aparentemente, as comunidades dessa região perderam essas formas originárias de aquisição floral e das bebidas. Segundo nosso informante, Juan Torres, e nossa própria constatação, tanto as bebidas quanto as flores são adquiridas de duas formas: seja pelos parentes dele que se deslocam até o mercado da comunidade de Auray ou ao mercado maiorista da cidade de Huancayo, seja em forma de presente das visitas - incluímonos entre estas -, que por motivos (parentes, convidados, amizades) diversos participam das festividades.

\section{- O Violino}

O violino, como instrumento trazido da Espanha no século XVI, tem seu uso frequente nas festas de Santiago. As melodias são construídas em um intervalo trítono construído sobre uma tríade maior e muito raramente sobre uma tríade menor. No Santiago o violinista tem o costume de alternar a posição um e a quatro do violino. À guisa de exemplo, uma versão similar completa de uma peça musical do Santiago é mostrada por Raul Romero (1998, p. 33), vejamos ${ }^{13}$ : 


\section{Santiago}
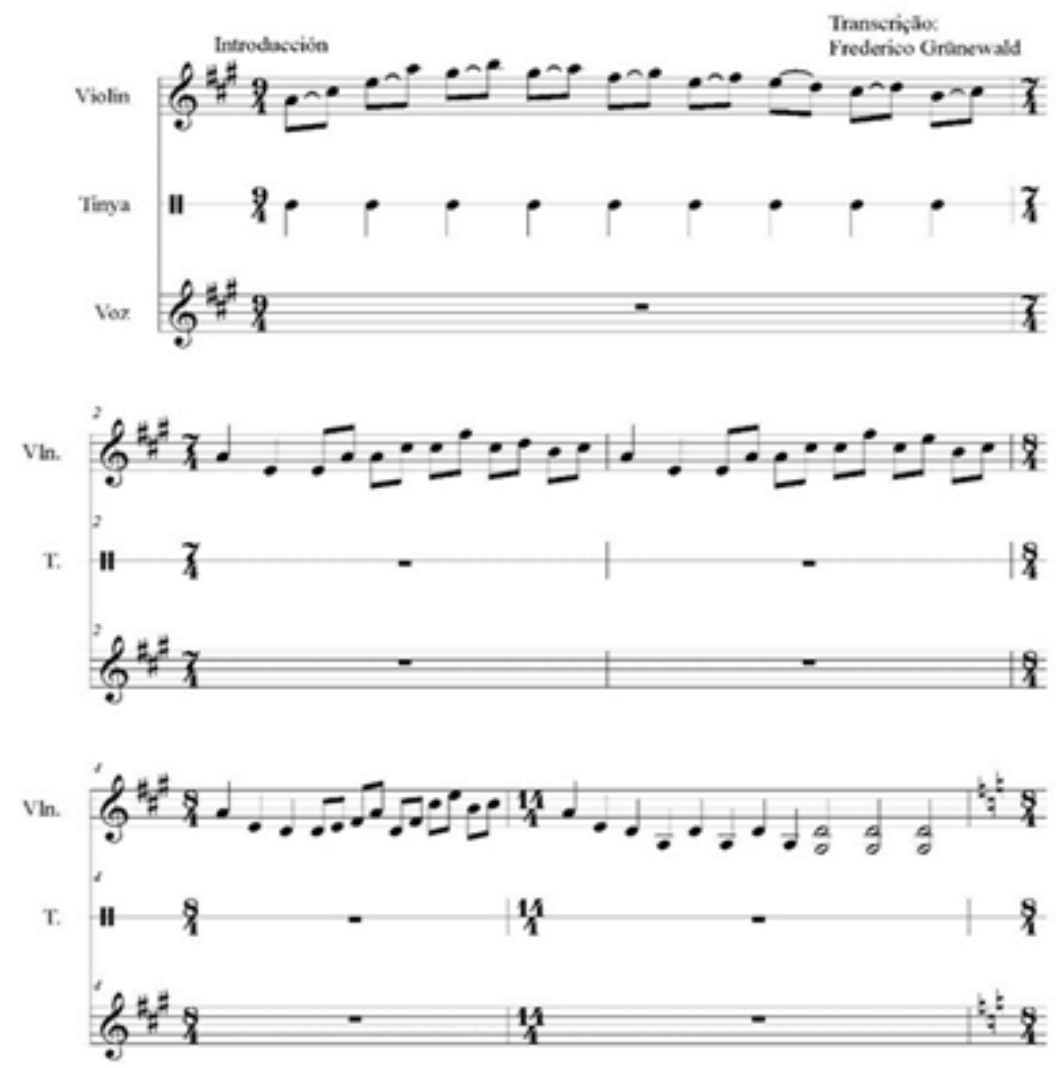

2
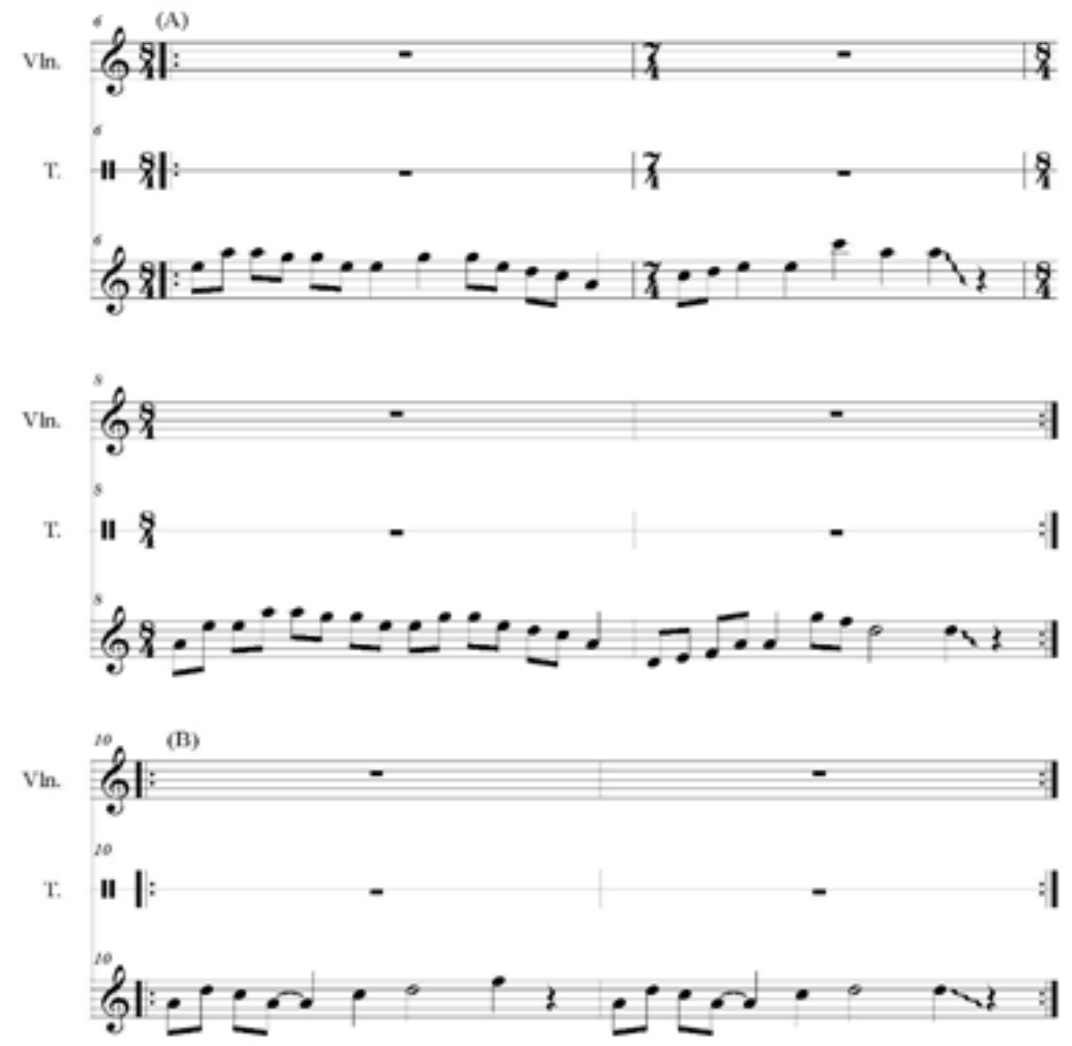

13 Esta versão foi transcrita pelo aluno Frederico Cunha Grünewald Zarantoneli do $8^{\circ}$ semestre do Departamento de Música do Instituto de Artes e Design da Universidade Federal de Juiz de Fora em Minas Gerais. 
Segundo Raul Romero, essa versão inclui uma introdução em violino, a mesma que caracteriza cada tono. Apesar de a introdução ser sempre a mesma para todos os tonos, em quase todos os casos observados pelo autor os tonos são originais e distintivos uns dos outros (1998, p.32). Em nosso caso, a execução musical começa com o violino, logo o wakrapuku sugere a melodia da canção, enfatizando seus principais sons harmônicos: a tônica ou a quinta. Nem sempre o wakrapuku pode ser afinado com o violino, é por isso que executa tons diferentes do violino e da cantora.

Dos três instrumentos acima mencionados, o wakrapuku só é o único que pode ser tocado nessa ocasião. Desse modo, o fato de que essa música especializada só apareça nesse contexto reafirma a ideia de que o ritual Santiago é uma unidade indivisível de ação ritual e som.

\section{Funções simbólicas e sociais do Santiago}

Sabemos que o ritual Santiago, está dividido basicamente em duas partes: a véspera e o dia central. O esquema a seguir apresenta uma síntese da sequência dos rituais observados na comunidade camponesa de Auray:

\section{Véspera:}

a) Os rituais do Huaca-Jorqoy e do Pagapu;

b) Constituição da mesa ritual e períodos de descanso;

c) O Velakuy: dança noturna e os passeios

\section{Dia central: canções dos animais}

a) O Luci-Luci;

b) O Cintachikuy.

$\mathrm{Na}$ sequência ritual da véspera, durante o desenterrar das huacas (Huaca-Jorqoy), a constituição da mesa ritual e o Velakuy, os participantes dançam e bebem na própria casa, bem como nas visitas aos parentes e vizinhos até altas horas da noite. Para cada fase do ritual são executadas melodias especiais. Assim, o ritmo para dançar a constituição da mesa ritual e o Velakuy é frequentemente chamado de shacatán (sapateado forte). O pasacalle (arrastado) é quando os músicos e os participantes andam serpenteando pelas ruas para as visitas aos parentes e vizinhos. Este último acontece quando o grupo abandona a casa: tocando a Tinya e os demais instrumentos, cantando, "guapeando" e dançando, dirigem-se à casa da dona Mirta, vizinha escolhida na ocasião da pesquisa para realizar a visita. No caminho bebe-se e chacchase (mastiga-se) coca. Diante da porta, o grupo cessa de dançar e canta as letras oportunas demandando sua recepção. A seguir, valemo-nos das letras recolhidas por Sérgio Quijada (1985) para interpretar seu significado:

Chayraq chayraqmi chayamuchkayki

Recém acabei de chegar a você,

ichu sullalla rurusqaymanta, após ter bebido as gotas do ichu,

sacha rurullan rurusqaymanta. após ter comido o fruto das árvores.

Amam siñura rabiakunkinchu, Minha senhora, não vá ficar brava,

amam siñura piñakunkinchu, minha senhora, não vá se incomodar,

fastidiusulla runalla nispa, chamando-nos de homens inoportunos

uma nanaylla warmita nispa. ou dizendo: mulheres, são dores de cabeça.

Mamam siñura fastidio kaychu

Não é que sejamos inoportunos, minha

hina kustumbri kallasqanraykum senhora, assim é o costume, por isso temos

chayaykamuyki, yaykuykamuyki. chegado e ingressado (a tua casa).

O primeiro parágrafo anuncia a chegada, assim como reflete a dor do pastor acumulada durante o ano. Em seguida, justifica-se essa dor 
de maneira comportada, reiterando que não se está fazendo outra coisa que não esteja nos preceitos do costume. Consequentemente, deve ser permitido e aceito, por isso o "amam siñura piñakunkinchu; hina kustumbri kallasqanraykum chayaykamuyki". Quando inquiridos os músicos, a cantora confirma-nos essa prática: "Assim é o costume, eles têm que abrir a porta, não têm por que se enfadar. Assim como a chave é feita para abrir o cadeado, estas canções abrem o coração do visitado, ele tem de seguir respeitando o costume".

Logo, dentro da casa, o texto da canção obtida por nós, ilustra-nos outra norma desse costume:

\section{Aqata wisimuy Marianitascha \\ Recebe a chicha Marianita, \\ achakatapas asllatapas, \\ seja pouco ou muito, \\ wisimuy Marianitascha, recebe Marianita, \\ chuyutapas putkatapas, \\ seja suja ou limpa, \\ wisimuy Marianitascha. \\ recebe Marianita.}

Por meio deste canto se ordena trazer a chicha para ser servida aos visitantes. É necessário salientar: já no interior da casa a bebida preferida é a chicha, posto que com ela se canta e se dança até transpirar, ainda mais quando se gera uma competição entre os grupos que coincidiram à mesma casa. Nesse caso, quanto maior o repertório de canções maiores as oportunidades de sair-se vitorioso. Após ter dançado e bebido em abundância, o grupo anuncia sua retirada cantando a seguinte canção:

\section{¡Pagaykapuy! ¡Pagaykapuy! qamia qamia tragunmanta, ¡Pagaykapuy! ¡Pagaykapuy! gamia qamia aqanmanta.}

\section{Pagarei! Pagarei! por seu trago malfeito \\ Pagarei! Pagarei!}

por sua chicha insípida.

Yanqañataq rimawachawan traguywanmi sinkan nispa, yanqañataq parlawachwan aqaywanmi sinkan nispa.

Não vá comentar que nos embriagamos com seu trago,

não vá falar que nos embebedamos com seu trago.

Sinkaspayqa sinkaruyman puyñuntinta upiaspaycha, sinkaspayqa sinkaruyman urpinta tumaspaycha.

De embriagar-me, me embriagaria tomando o cântaro cheio, de embebedar-me, me embebedaria tomando o cântaro todo.

Percebemos, com esta canção se consegue, sutilmente, dois objetivos: primeiro fazer com que o dono os despeça com mais chicha e cachaça, mesmo se a recepção foi satisfatória. O segundo objetivo exprobra e reprocha o dono da casa; seu objetivo é fazê-lo sentir-se mal no caso de a recepção não ter sido do agrado dos visitantes. Nesse caso, é utilizada para censurar comportamentos dos indivíduos que, atualmente, vão contra as normas do Santiago. "don" Juan nos diz: "A mim me dá vergonha quando cantam essa canção, por isso quando um grupo chega tento atendê-los e despedi-los bem". Por sua vez, o tocador do violino (violinista) relata-nos: "Quando cantamos assim, os donos da casa sacam (chicha e trago) de onde seja", sempre sentenciando: "Assim é o costume". Interpretamos nestes relatos que nem sempre é assim, isso só acontece quando não foi do agrado das visitas.

Após participar da visita a dona Mirta, por volta das quatro da manhã retornamos à casa de "don" Juan para dar uma interrupção nos passeios e preparar-nos para a seguinte unidade ritual que se aproxima: o Luci-Luci. O ritual LuciLuci e as visitas que lhe precedem também são traduzidos como "vencer a montanha". Segundo "don" Juan, "o Luci-Luci é feito porque o Wamani 
sai a recolher seus animais, então nós o fazemos para que o Wamani não os leve". A letra de um Luci-Luci recolhida por Sérgio Quijada (1974) o ilustra pertinentemente:

\section{Luci luci}

Nam ya pacha achikllanña ay, luci luci

Nam ya pacha rayamunnña ay, luci luci

Ñañllaypas llalliyyaman

ay, luci luci.

Kondor waman llalliyyaman ay, luci luci

Pillpintuchan llalliyyaman

ay, luci luci

Awkish tayta jitallamay

ay, luci luci

yana torota jitallamay

ay, luci luci

Yanallaypas llalliyamay

ay, luci luci

paysanaypas llalliyamay

ay, luci luci

\section{Luzeiro, luzeiro}

O mundo vai aclarando

Ai, luzeiro, luzeiro!

A aurora vai raiando

Ai, luzeiro, luzeiro!

amanhece minha irmãzinha

Ai, luzeiro, luzeiro!

O condor e o falcão me vencem

Ai, luzeiro, luzeiro!

A borboleta me vence

Ai, luzeiro, luzeiro!

Senhor avô, arroja (joga)

Ai, luzeiro, luzeiro!

Arroja meu touro preto

Ai, luzeiro, luzeiro!
Até minha amada madrugou

Ai, luzeiro, luzeiro!

E também minha paisana

Ai, luzeiro, luzeiro!

Esta canção entoada e dançada pelos participantes possui um significado: os homens vencem a montanha, e ganham do Wamani o gado que será então para os homens, que prosperarão graças ao Luci-Luci e ao Santiago como um todo. "Adiantando-se", desse modo, os homens ganham o gado, posto que este, em princípio, pertence ao espírito da montanha. O Luci-Luci, então, além de ser um rito propiciatório, de purificação, é também uma manifestação de rivalidade entre os homens e os deuses da montanha. Para a marcação do gado no dia central, cada animal tem uma tonadilha específica que, segundo Raul Romero (1998), pode ser chamada de Tangra (Sinal). Para dona Julia os ritmos específicos do sinal são chamados de señalay.

Outras duas melodias do Santiago são: a canção mesa mastay (melodia da elaboração da mesa do ritual de bênção, após o Luci-Luci) e a canção do Cintachikuy. Vejamos, na unidade ritual de bênção da mesa, são dispostos sobre a manta diferentes componentes cerimoniais: os kintos (melhores folhas de coca), a chicha, a toqra ou llipt'a (cinzas de prantas nativas), uma caixinha de fósforos, uma caneca e um prato vazio. $\mathrm{Na}$ simbologia Aurina, segundo "don" Juan, a coca é a "forragem", a chicha é o "soro", a cachaça é "o leite", e a toqra é o "sal preto".

Prévia à colocação das cintas, "don" Juan pega a coca da mesa ritual, reparte para todos os participantes chaccharem (mastigarem). Nessa unidade ritual, a escolha das melhores folhas de coca - o kinto - merece a canção mesa mastay. Estas são suas letras:
Mesata mastachiy
mamapatrona,
kukata kintuykuy mama
pastora,
ama piñakuspalla mama
pastora.

Ordena estender a mesa, senhora patroa,

escolhe o kokakinto, senhora patroa, 
mas, sem enfadar-se, senhora patroa, recebamos a coca (para escolher), senhora patroa.

As pessoas que escolhem kokakinto representam os pastores e as pastoras, e as folhas escolhidas representam o gado; dependendo do tamanho e da grossura, são considerados machos ou fêmeas. A canção mesa mastay reproduz, fundamentalmente, as relações de trabalho, principalmente entre o dono do gado e o pastor.

No dia 26 de julho, começam os preparativos do Cintachikuy, a canção dessa unidade ritual nos é dada pelas informações do antropólogo Juan Carlos Cóndor que, solícito, atendeu nossas inquietações etno-linguísticas:

\section{Chalaykuy chalaykuy señor alano ichuqchanmanta alliqchallanman, alliqchallanmanta ichuqchanmanta. Chuqarquy Chuqarquy \\ llullu muqu maqtata chaynata chuqarquy, anku kichka hawabman, rumi ranra ukuman. \\ Allinchallata aritichiway, ayrillayman hinata buina muzalla purinaypaq. Waqrachanniyta waqram ninkichu waqrachanniyqa cristal vasuchan, pilucanniyta pilum ninkichu pilucanniyqa waylla ichucham, rinrichanniyta, rinrim ninkichum rinrichanniyqa quri vasucham, sinqachannyta sinqam ninkichum sinqachanniyqa ñawim pukiucham, wiksachanniyta wiksamninkchum wiksachanniyqa siñal putucham, silluchanniyta sillum ninkichum silluchanniyqa qulqi kupacham, qalluchanniyta gallum ninkichum qalluchanniyqa iskubillacham, chupachanniyta chupam ninkichum chupachanniyqa wandira piruanam.}

Apanhá-lo e deitá-lo senhor, segurando-o pela esquerda e pela direita, tomando-o pela direita e pela esquerda. Jogá-lo, atirá-lo a esse moço fraco e sem força assim jogá-lo

por cima dos espinhos,

no meio do pedregal.

Coloca-me bem os pendentes,

põe-me bonito os pendentes.

Em harmonia a minha boa presença

para andar feito uma boa moça.

Acreditas que seu chifre é um chifre,

mas é um copo de cristal,

acreditas que seu pêlo é pêlo

mas seu pêlo é waylla ichu,

acreditas que sua orelha é orelha

mas sua orelha é copo de ouro,

acreditas que seu narizé nariz

mas seu narizé olho do manancial,

acreditas que sua barriga é barriga

mas sua barriga é a cabaça do sinal

acreditas que sua unha é unha

mas sua unha é taça de prata.

acreditas que sua língua é língua

mas sua língua é escovinha,

acreditas que seu rabo é rabo

mas seu rabo é a bandeira peruana.

Esta é uma canção que poderíamos denominar "mimética". Nela reproduz todos os momentos e fatos que apresentam o desenrolar da unidade ritual Cintachikuy (colocação das cintas). Começa no momento em que os walars ou maqtas (jovens solteiros) apanham o animal ou pela direita ou pela esquerda (eles sabem que é mais fácil reduzir o animal introduzindo os dedos nos orifícios nasais); a luta que se estabelece com o animal para segurá-lo; a queda de algum walar que muitas das vezes é arremessado acima dos espinhos ou do pedregal, sendo ridicularizados de fracos e llullu muqu (sem força), com o propósito de encorajá-los; a mesma colocação das cintas deve ser feita com vontade e graça. Finalmente, enaltece-se o animal comparando-o com objetos de valor material (ouro, prata etc.) e de valor simbólico, waylla ichu (cabaça do sinal e bandeira) que representam as partes do animal.

As melodias mencionadas confirmam, no processo ritual, que não só existe a unidade de gesto e som, mas denota com as letras das canções sua reprodução ritual. Nenhuma unidade ritual do Santiago é realizada sem música; embora em muitos dos casos não receba um nome especial, ela adota o nome da unidade da qual faz parte, 
este é outro índice de unificação entre ação ritual e som.

As canções aqui expostas fazem parte de um conjunto de músicas que, dependendo da região, variam, mas que sempre tentarão apresentar com frequência e prioridade o conteúdo normativo nelas expresso, pautando atitudes a assumir: por um lado, prescrevendo o respeito aos padrões de comportamento estabelecidos pelo costume, pela tradição cultural. Por outro lado, cumprindo a função de criticar, repreender ou censurar a atitude daqueles que transgrediram os padrões tradicionais e cujas relações humanas se verão afetadas significativamente, sobretudo em uma sociedade em que a solidariedade, a reciprocidade e a cooperação são de fundamental importância. Transferimos a palavra a Juan Garcia:

(...) a tradição cultural de um povo, ao constituir-se no meio eficaz de socialização do homem, forma a personalidade individual e coletiva dos atores sob os marcos de sua própria identidade, que norma e pauta o comportamento de seus integrantes, controlando e sancionando as transgressões a seus valores e padrões de vida estabelecidos" (1996, p.12).

Outrossim, aproveitando-se da licença que concede os momentos mais festivos do Santiago, essas canções estabelecem um diálogo musicalizado, um jogo de palavras, para solicitar e representar desejos que de outro modo seriam impossíveis de expressar verbalmente. Os diferentes momentos, passagens, suas canções e práticas da festa de Santiago, por nós pesquisados, constituem uma unidade inseparável de "gesto e som". Para cada unidade ritual existe uma canção especializada que a reproduz; salvo exceções, as canções não podem ser executadas indistintamente em outro contexto que o seio da festa e, menos ainda, fora dela (ex.: o Luci-Luci). Além disso, esses cantos reproduzem vivências, problemas da comunidade e sua própria interrelação com a natureza, isto é, a relação entre o dono do gado, o gado e o Wamani. Finalmente, nas músicas estão presentes relações de reciprocidade, visto que os participantes retribuem, pagam ou agradecem não só ao deus tutelar, mas também se chama a compartilhar aos participantes aquilo que se possui.

\section{Do rito à festa: transformações contemporâneas das músicas do ritual Santiago em Auray}

Perante o descrito anteriormente, cabe a seguinte reflexão, será que o rito e a música do Santiago no Vale do Rio Mantaro têm resistido às transformações do sistema industrial, à modernização, à urbanização, ao aparecimento de outros movimentos religiosos e, ao impacto das novas tecnologias da comunicação? Por que o camponês do Vale do Rio Mantaro, que muda perante outras situações, tem mantido o ritual Santiago inalterável, apesar do intenso processo de integração na economia nacional? Parte da explicação pode ser encontrada no argumento de que a música ritual ou religiosa não pode mudar sem alterar outros aspectos do mesmo ritual; Alan Merriam (1964) e Bruno Nettl (1983). No entanto, essa reflexão só explica por que o som musical não muda, mas deixa em aberto por que o mesmo ritual - como entidade total de gesto e som - e os valores implícitos nele têm resistido às mudanças, permanecendo um lugar essencial na vida dos povoadores do Vale do Rio Mantaro. Uma reinterpretação parcial continua sendo o camponês mestiço da região, capaz de aceitar e adotar os benefícios da urbanização e da modernização e, inserido na economia nacional, ainda está vinculado a rituais como o Santiago; pois, por meio dele comunica-se com as forças abstratas para propiciar a fertilidade animal.

No entanto, nossas pesquisas recentes realizadas em 2016, percebem que as músicas do ritual Santiago têm sofrido alguns deslocamentos e mudanças culturais que poderiam ser ilustrados sobre a visão de mudança cultural aferida por José Maria Arguedas (1968):

$\begin{array}{lcc}\text { Contexto Ritual } & \text { Festas } & \text { Midia } \\ \begin{array}{c}\text { Comunidade } \\ \text { Andina }\end{array} & \text { Região Rural } & \text { Nação }\end{array}$

Vejamos, a música no contexto da comunidade está estreitamente vinculada ao cotidiano e aos ciclos cerimoniais de seus habitantes. Entretanto, muitas dessas expressões musicais têm sido extraídas de seu contexto original para serem inseridas no sistema de festas de alcance regional. 
O sistema de festas ${ }^{14}$ serve como um veículo ideal para disseminar toda expressão musical através do Vale do Rio Mantaro. Quando os processos de migração se intensificam e ondas de habitantes rurais invadem os centros urbanos e de mineração, as expressões musicais mais populares do vale permitem o acesso à indústria fonográfica. A partir disso, a indústria populariza essa expressão musical através da rádio, internet, redes sociais a outras regiões do país, concedendo cobertura nacional e sucesso comercial entre os consumidores migrantes.

Nesse contexto, contemporaneamente, temos observado a existência do santiagos como gênero musical popular, que se desenvolve a partir do ritual. De um lado, ubíquas orquestras típicas estão executando tonadilhas do ritual Santiago, chamadas santiagos, nas festas do Vale do Rio Mantaro. O mesmo percurso de transformações culturais e deslocamentos, já sofreram músicas como a "palpa" (casamento) e a "minka" ou "safacasa", (modelo de reciprocidade e coletivismo de trabalho) cujas raízes se remontam à época préhispânica, hoje, reinterpretados e incorporados, adotam um único estilo regional nas mãos do repertório das orquestras típicas da região do Vale do Rio Mantaro. O papel determinante de conjuntos instrumentais - orquestras e bandas de músicos -, de disseminar e popularizar as músicas do ritual Santiago, previamente relevantes somente em comunidades específicas, não deve ser ignorado. Hoje, não é raro encontrar santiagos no mercado midiático de um para outro lado da nação.

De maneira igual, a difusão desta festa tradicional está sendo veiculado através das plataformas YouTube e Facebook. Sobre a apropriação destas duas tecnologias de comunicação pelas comunidades camponesas, o antropólogo peruano Oscar Espinosa (1998, 2011), resumidamente nos diz, que um dos motivos pelos quais as tradições culturais vêm se popularizando é o poder performático que o audiovisual passa a ter no contexto político e de turismo. No caso dos santiagos, pelas nossas análises imagéticas particulares, nos indicam que essa difusão está orientada para o étnico e o turístico. Assim sendo, as plataformas acima mencionadas, têm se convertido em espaços de auto representação ${ }^{15}$ e autoafirmação do "Outro"16, esvaziando o político a um conjunto de representações culturais e étnicas com forte apelo económico. Isto é, os santiagos, têm, no YouTube e Facebook, a promoção turística e a visibilidade desses grupos como atores sociais e coletividade com capacidade de ação cultural.

Pelo mencionado, uma reflexão final, os santiagos, vêm adquirindo um estilo regional em detrimento de particularidades locais uma vez incorporados no repertório da orquestra típica folclórica. O que tudo indica, a presença das novas tecnologias da comunicação no caso do Vale do Rio Mantaro nos confirma uma simbiose entre as crenças tradicionais e a contemporaneidade.

\section{REFERÊNCIAS BIBLIOGRÁFICAS}

ARGUEDAS, José María; RESCANIERI, Alejandro, O. "La posesión de la tierra, los mitos

14 Segundo alguns autores, as festas e celebrações são formas de catarse social e se produzem em momentos de liminaridade (Turner, 1974). Nelas, o homem deixa de fazer o cotidiano para festejar, celebrar, comemorar, lembrar, relembrar, esquecer e modificar fatos, situações ou até mesmo transformar momentos vitais, que provocam nos homens, estados de angústia necessários de confrontar. É uma etapa onde o indivíduo desenvolve a "disposição criativa, festiva e fantástica" (Cox, 1972) e pede "licença à rotina" (Leach, 1978).

15 A respeito disso, nos alinhamos com a pesquisadora Catherine Russel (1999), quando aponta que na produção audiovisual de não-ficção contemporânea, o "Outro" é um sujeito que está nos próprios cineastas, em suas famílias e suas comunidades. A pesquisadora reenquadra a etnografia como um autorrepresentação, na qual todo e qualquer sujeito é capaz de entrar nas formas textuais do discurso audiovisual, anunciando um rompimento total com os preceitos colonialistas da etnografia e um forte entusiasmo pelas várias possibilidades de fazer dela um tipo de antidocumentário. A autoetnografia é conceituada, segundo Russel, como "um veículo e uma estratégia para desafiar formas impostas de identidade e explorar possibilidades discursivas de subjetividades não autorizadas”. Essa abordagem será utilizada em futuras reflexões sobre formas alternativas de construção do "Eu" nas plataformas de YouTube e Facebook.

16 À diferença da antropologia tradicional, na qual o “Outro”, isto é, os sujeitos, as comunidades e os grupos sociais eram vistos como uma alteridade exótica, verdadeiros objetos de pesquisa e muito distantes do universo do antropólogo, hoje, esse "Outro", vem assumindo, um papel ativo, tornando-se ele mesmo realizador de sua própria cultura. . 
poshispanicos y la visión del universo en la población monolingüe quechua”, en Les problèmes agraires des Amériques Latines, París, 1965

"De lo Mágico a lo Popular, Del Vínculo

Local al Nacional”. El Comercio (Suplemento Dominical), Lima, 30 de junio de 1968.

"Dos estudios sobre Huancayo". In:

Cuadernos de Investigación. Huancayo, UNCP, 1984.

BRANDÃO, Carlos Rodrigues. Somos as águas puras. SP, Papirus, 1994.

COX, Harvey. La fiesta de locos, Península, Editorial Barcelona, 1972.

ELIADE, Mircea. “El mito del eterno retorno”. In: Obras maestras del pensamiento contemporáneo, Libro n 24, Proyectos Editorial, México, 1981. O Sagrado e o Profano: A essência das religiões. São Paulo, Martins Fontes, 2001.

ESPINOSA, Oscar. "Los pueblos indígenas de la amazonía peruana y el uso político de los medios de comunicación". América Latina Hoy, No 19, pp 91-100. Salamanca, 1998.

FUENZALIDA, Fernando. "Santiago y el Wamani: aspectos de un culto pagano em Moya". Em Debates em Antropologia, no 5, Lima: PUCP, 1980.

GEERTZ, Clifford. A interpretação das culturas. RJ, LTC, 1989.

LEACH, Edmund. Cultura e Comunicação. Rio de Janeiro: Editora Zahar, 1978.

MARZAL, Manuel.ElSincretismoiberoamericano. Lima: PUC, 1985.

MERRIAM, Alan. The Anthropology of Music. Evanston: Northwestern University Press, 1964.

MUNN, Nancy. "Symbolism in a Ritual Context: Aspect of Symbolic Action". In: Honigmann (ed.), Handbook Of Social and Cultural Anthropology, 1974.

NETTL, Bruno. The Study of Ethnomusicology:
Twenty-Nine Issues and Concepts. Urbana: University of Illinois Press. 1983.

PINILLA, Enrique. "Informe sobre la música en el Perú". In: Historia del Perú. t. IX, JMB, Barcelona, 1981.

QUIJADA, Sérgio. Tayta Shanti. Huancayo, Edit. Sebastian Lorente, 1974. . Estampas Huancavelicanas. Lima:

DUGRAFIS, 1985.

RESCANIERI, Alejandro, O. Símbolos y ritos andinos: um intento de comparación con el área vecina amazónica. Antropologica 3, PUCP, Lima: 1985.

ROMERO, Raúl. "cambio musical y resistencia cultural en los Andes centrales del Perú". In: Música, Danzas y Máscaras en los Andes. Lima, PUCP, 1998.

RUSSEL, Catherine. Experimental ethnography: the work of film in the age of video. Londres: Duke University Press, 1999.

TAIPE, Néstor. Informe de Investigación. Huancayo, UNCP, 1982.

TURNER, Victor. O processo ritual: estrutura $e$ antiestrutura. Petrópolis, Vozes, 1974.

URBANO, Henrique O. "La Representación Andina del Tiempo y del Espacio". Allpanchis, $\mathrm{n}^{\circ}$ 7, Instituto Pastortal Andina, Cuzco, 1974.

VALCÁRCEL, Luis. Historia del Perú antiguo a través de la fuente escrita. Barcelona: JMB, t. III, 1984. 